\title{
The Differential Diagnosis of a Patient with Unilateral Congenital Facial Paralysis: 3q21 Deletion
}

\author{
Nagehan Aslan, $\mathbf{M D}^{1}$, Cigdem Sivrice, $\mathbf{M D}^{2}$ and Ahmet Rifat Ormecı, $\mathbf{M D}^{3}$ \\ ${ }^{1}$ Department of Pediatrics, Cukurova University, Turkey \\ ${ }^{2}$ Department of Pediatrics, Mustafa Kalemli State Hospital, Turkey \\ ${ }^{3}$ Department of Pediatrics, Suleyman Demire l University, Turkey
}

Submission: September 19, 2017; Published: January 19, 2018

*Corresponding author: Nagehan Aslan, epartment of Pediatrics, Cukurova University, Faculty of Medicine, Turkey,

Email: nagehan_aslan@hotmail.com

\begin{abstract}
A 1-year-old female with unilaterally congenital weakness in the facial muscles was referred to us and we have studied the literature about facial paralysis for differantial diagnosis in the light of this case. There are several described causes of facial nerve paralysis in children, as it can be congenital (due to delivery traumas and genetic or malformative diseases) or acquired (due to infective, inflammatory, neoplastic, traumatic or iatrogenic causes) and can be unilaterally or bilaterally. Nonetheless, in approximately $40 \%-75 \%$ of the cases, the cause of unilateral facial paralysis still unknown and remains idiopathic. The differential diagnosis of CFP should include Moebius syndrome, hereditary congenital facial paralysis (HCFP), and congenital ptosis. Herein we describe a patient that presented with unilateral CFP; in addition, the differential diagnosis of CFP and genetic analysis are discussed in the light of the relevant literature.

Keywords: Congenital Facial Paralysis; Unilateral; CGH Array; Moebius Syndrome; Microdeletion
\end{abstract}

\section{Introduction}

Pediatric facial nerve paralysis can be congenital or acquired. Congenital facial paralysis (CFP) originates from a structural defect in the facial nerve nucleus and/or cranial nerve, and is often associated with partial or complete absence of the facial nerve. CFP can occur unilaterally or bilaterally. Hereditary congenital facial palsy and Moebius syndrome is considered in the differential diagnosis. Moebius syndrome (MBS) is a rare congenital disorder characterized by facial palsy with limited gaze abduction due to abducens paralysis. Hereditary congenital facial palsy (HCFP) is an autosomal dominant congenital dysinnervation syndrome, recognizable by the isolated dysfunction of the seventh cranial nerve. In this case report we offered a pediatric patient with unilateral CFP and we want to draw attention to the importance of genetic analysis.

\section{Case}

A 1-year old female presented with the inability to close her right eye and the left corner of her mouth moving downwards when crying, both of which were present since birth. The G2A1P1Y1 infant weighed $2800 \mathrm{~g}$ at birth and was born fullterm via normal spontaneous vaginal delivery to a 20 -year old mother. The patient's parents were not consanguineous and the mother reported a negative history of medication use during the pregnancy. Physical examination showed hypertelorism and right facial paralysis (Figure 1). There weren't any cardiac or extremity anomalies. Comprehensive laryngoscopic examination was negative for vocal cord paralysis. Hearing test, routine laboratory tests, and abdominal ultrasonography findings were normal.

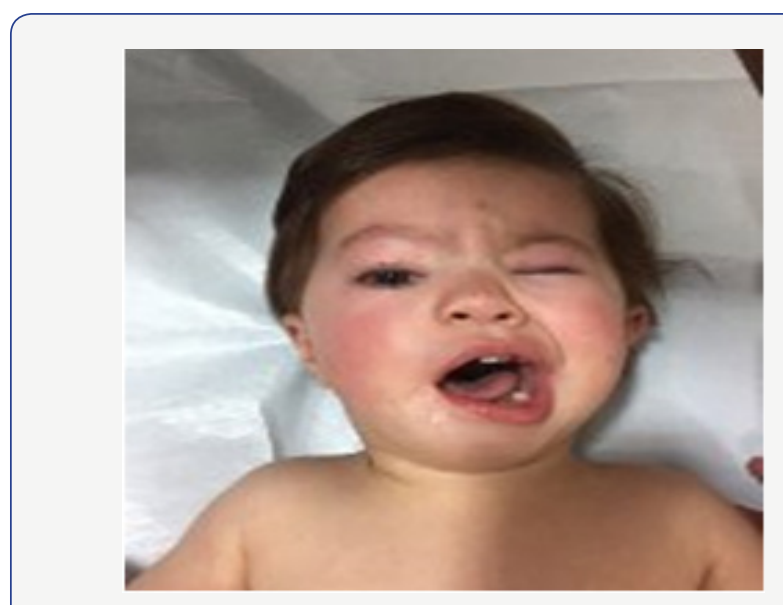

Figure 1: When crying, the right eye could not be closed and the left side of the mouth moved downwards and the right nasolabial sulcus disappeared.

Ophthalmological examination showed dacryostenosis and ectropion, and the patient was scheduled for surgery. Cranial MRI was negative for structural abnormality of the brain and 
brain stem. Temporal bone CT showed relatively slight right facial nerve symmetry (Figure 2). Karyotype analysis was negative for numerical and structural anomalies. As the patient had isolated facial paralysis, there weren't any phenotype characteristics or concomitant dysmorphic findings, cranial MRI showed no structural abnormality in the brain and brain stem, Moebius syndrome was eliminated from the differential diagnosis and CFP was considered. Genetic analysis was performed using the CGH array method, which showed an 1867 deletion in 3q21.1q21.2 locations in the region, including the genes SEC22A, ADCY5, MYLK, ROPN1, UMPS, MUC13, PTPLB, CCDC14, KALRN, ITGB5, HEG1, and $S L C 12 A 8$. In order to determine if the patient acquired CFP via hereditary transmission the parents were referred for genetic testing. The test detected normally.

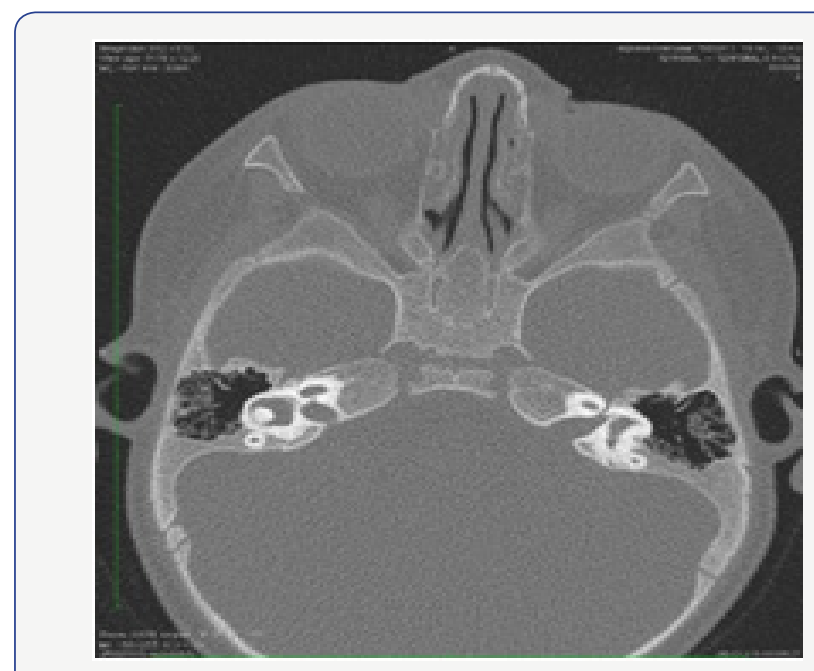

Figure 2: Proportion of mechanical ventilation.

\section{Discussion}

CFP is characterized by abnormal eye, eyelid, and facial movements, and the most common cause is perinatal trauma [1]. The most frequently reported risk factors associated with CFP are being the firstborn child, birthweight $>3500 \mathrm{~g}$, use of forceps during delivery, caesarean delivery, and prematurity. CFP can be hereditary or sporadic. The parents of the presented case were referred for genetic testing to determine if hereditary transmission occurred.

Moebius syndrome is the primary consideration in the differential diagnosis of CFP. Previously, CFP was accepted to be a variant of Moebius syndrome, but recent studies have shown that CFP and Moebius syndrome are two distinct diseases [2]. Moebius syndrome is characterized byabducens paralysis and other systemic abnormalities, in addition to facial nerve paralysis. In the majority of cases Moebius syndrome is a congenital defect involving the 6 th and $7^{\text {th }}$ cranial nerves bilaterally, and occasionally unilaterally [3], whereas less frequently, the $3^{\text {rd }}, 4^{\text {th }}, 5^{\text {th }}$, and $9^{\text {th }}$ cranial nerves are involved.

Musculoskeletal system abnormalities are the primary additional systemic anomalies accompanying Moebius syndrome [4-6], although cardiac anomalies, ocular anomalies, and craniofacial anomalies can be seen. The presented case had ectropion and dacryostenosis, which were surgically corrected by the ophthalmology department. The patient also had hypertelorism, but laryngoscopic examination was normal. As Moebius syndrome is rarely seen and its etiopathogenesis is not fully known, the underlying pathological process remains to be fully understood [7]. When considered as a whole, a localized developmental defect in the brain stem complex forms the basis of the pathogenesis of Moebius syndrome [8]. In addition to sporadic cases of Moebius syndrome, familial cases of autosomal recessive, autosomal dominant, and X-related recessive transmission have been reported [6]. Radiological imaging in patients with Moebius syndrome shows inferior brain stem hypoplasia, a hypoplastic cerebellum, focal necrosis/calcifications of the central nerve nuclei, and flattening of the fourth ventricle layer [10]. In the presented case cranial MRI showed the absence of structural anomalies in the brain and brain stem.

Genetic analysis is important in the differential diagnosis of CFP. In cases of unilateral and bilateral CFP, microarray analysis is recommended for findings deletions that are not found via chromosome analysis. Peripheral karyotype analysis in the presented case was normal, whereas via the CGH array method a microdeletion was found in the 3q21.1q21.2 location. Genetic analysis of Moebius syndrome patients shows that the 13q12-q13 band region (especially microdeletions in $F G 9, G S H 1$, and $C D X 2$ ) is primarily responsible for the disease [11].

Some studies have reported that de novo mutations in PLXND1 and REV3L cause Moebius syndrome [12]. Moreover, an association between HCFP, and 3q21.2-q22.1 and 10q21.3-q22.1 chromosome locations has been observed $[13,14]$; however, at the time these studies were conducted HCFP was considered a variant of Moebius syndrome and the researchers associated these locations with Moebius syndrome. A microdeletion was noted in the 3q21.1q21.2 location in the presented case and genetic analysis of the parentsis expected to indicate hereditary transmission of CFP.

In conclusion, CFP and Moebius syndrome must be carefully differentiated. Moreover, genetic analysis of CFP patients and identification of novel associated genes are of critical importance.

\section{Acknowledgement}

We would like to thank to the patient and her family for their permission to using their data in this case report.

\section{Conflict of Interest}

No conflict of interest was declared by the authors.

\section{Financial Disclosure}

The authors declared that this study has received no financial support. 


\section{References}

1. Pavlou E, Gkampeta A, Arampatzi M (2011) Facialnervepalsy in childhood. Brain Dev 33(8): 644-650.

2. Lima LM, Diniz MB, dosSantos-Pinto L. (2009) Moebiussyndrome: clinicalmanifestations in a pediatricpatient. Pediatr Dent 2009;31:289-293.

3. Verzijl HT, van der Zwaag B, Lammens M, ten Donkelaar HJ, Padberg GW (2005) The neuropathology of hereditary congenital facial palsy vs Möbius syndrome. Neurology 64(4): 649-653.
4. Purushothamdas S, Rayan F, Gayner A (2009) Correction of neglected club foot deformity in children with Moebius syndrome. J Pediatr Orthop B 18(12): 73-75.

5. Lindsay RW, Hadlock TA, Cheney ML (2010) Upper lip elongation in Möbius syndrome. Otolaryngol Head Neck Surg 142(2): 286287.

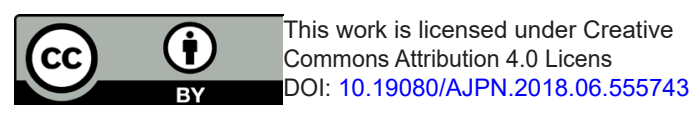

\section{Your next submission with Juniper Publishers will reach you the below assets}

- Quality Editorial service

- Swift Peer Review

- Reprints availability

- E-prints Service

- Manuscript Podcast for convenient understanding

- Global attainment for your research

- Manuscript accessibility in different formats

( Pdf, E-pub, Full Text, Audio)

- Unceasing customer service

Track the below URL for one-step submission https://juniperpublishers.com/online-submission.php 
